\title{
A CORPOREIDADE NO ENSINO DE TEATRO: PARA ONDE APONTAM OS PPCS DAS LICENCIATURAS EM TEATRO DAS UNIVERSIDADES FEDERAIS BRASILEIRAS?
}

\author{
CORPORALITY IN THE DRAMA TEACHING: the Educational Program of Course \\ of the drama degree of the brazilian federal universities point to where?
}

LA CORPOREIDAD EN LA ENSEÑANZA DE TEATRO: Para dónde apuntan los Proyectos Pedagógicos de las Licenciaturas en Teatro de las Universidades Federales Brasileñas?

\author{
Amanda Diniz Gonçalves \\ Licencianda em Teatro pela Universidade Federal do Tocantins (UFT). \\ amanda.diniz@uft.edu.br \\ Juliano Casimiro de Camargo Sampaio \\ Professor Doutor da Universidade Federal do Tocantins (UFT). \\ juliano.casimiro@uft.edu.br
}

RESUMO: Nesta pesquisa analisamos a natureza das referências bibliográficas básicas e complementares das licenciaturas em teatro das universidades federais brasileiras, bem como a presença de indicações sobre o trabalho do ator e sobre o ensino de teatro nos ementários das disciplinas que tomam o corpo como foco. Realizamos análise quantitativa e qualitativa de documentos (Projetos Pedagógicos de Curso). Resultou que tanto as bibliografias quanto as ementas das disciplinas analisadas estão consideravelmente mais voltadas para as práticas do ator do que para o ensino de teatro, bem como evidenciamos a ausência textual das palavras experiência, metodologia e didática no todo das ementas analisadas.

PALAVRAS-CHAVE: Licenciatura. Teatro. Ensino. Ementário.

ABSTRACT: In this paper we analyze the nature of the references of the degree in drama of the brazilian federal universities. We analyze too the presence of the indications about both the actor's work and the teaching of drama in the programs of the courses that take the body as focus. The methodology used was documental research with both quantitative and qualitative analyzes of the Educational Program of Course (EPC). Resulted that the references and the programs of studies of the analyzed courses are considerable more focused in the actor's work than in teaching drama. We noted too the absence of the following words: experience, methodology and didactic, in the analyzed programs of studies.

KEYWORDS: Degree. Drama. Teaching. Program of course.

RESUMEN: En esta investigación analizamos la naturaleza de las referencias bibliográficas básicas y complementarias de las licenciaturas en teatro de las universidades federales brasileñas, así como, la presencia de indicaciones sobre el trabajo del actor y sobre la enseñanza de teatro en los programas educacionales de las asignaturas que toman el cuerpo como foco. Realizamos análisis cuantitativo y cualitativo de los documentos (Proyectos Pedagógicos de Curso). Resultó que tanto las bibliografías cuanto los programas educacionales de las disciplinas analizadas están considerablemente más direccionados para las prácticas del actor que para la enseñanza de teatro, así como, evidenciamos la ausencia textual de las palabras experiencia, metodología y didáctica en el total de los programas de los cursos analizados.

PALABRAS CLAVE: Licenciatura. Teatro. Enseñanza. Programa de Curso.

$\overline{\text { Artigo recebido em janeiro de } 2016}$

Aprovado em março de 2016 


\section{1| INTRODUÇÃO}

Este artigo é resultado de pesquisa de iniciação científica (IC) da primeira autora com orientação do segundo autor. Com o plano de trabalho (IC) intitulado "Corpo e Construção de Conhecimento: a experiência estética na formação dos professores de teatro"1, que deu origem a esse texto, pretendíamos a verificação de como estão pensadas e explicitadas as relações entre corpo, criação teatral e educação em certas ementas e referências bibliográficas de disciplinas de curso de formação superior. A finalidade do estudo foi compreender o mapa conceitual e prático da formação dos futuros docentes em teatro sobre possíveis funções e naturezas para a inserção da experiência com teatro na escola, tomando como fio condutor da pesquisa realizada a ideia de que "É importante que o professor esteja consciente do teatro como um elemento fundamental na aprendizagem e desenvolvimento da criança e não como transmissão de uma técnica (BRASIL, 1997, p. 58). Nesta perspectiva, tomamos como referência a indicação presente nos Parâmetros Curriculares Nacionais sobre o ensino de teatro, bem como a premissa de que a inserção do teatro na escola atende, em grande medida, segundo o mesmo documento, à necessidade de ampliação das potencialidades corporais para contextos de expressão e comunicação, que optamos por centrar nossas pesquisas e análises nas relações entre corpo, criação e ensino, presentes nos Projetos Pedagógicos das licenciaturas em teatro.

Visto isso, as ementas analisadas foram aquelas descritas em Projetos Pedagógicos de Curso (PPC) das licenciaturas em teatro das universidades federais brasileiras, tendo como objeto as disciplinas que tomavam o corpo como foco, tais como: "Expressão Corporal"; "Técnicas Corporais"; "Corpo e Movimento". A pesquisa iniciou com o reconhecimento de quais eram as universidades federais brasileiras que ofereciam cursos de formação de professores de teatro (licenciatura em teatro ou equivalentes). Optamos por trabalhar apenas com cursos presenciais em atividade no ato da pesquisa (2014/2015). A escolha pelas instituições federais se deu por estarmos inseridos neste mesmo contexto de ensino e formação. Constatamos a existência de 24 instituições ofertantes do referido curso de formação: UNIRIO; UFOP; UFMG; UFSJ; UFU; UFG; UNB; UNIR; UFAC; UFPA; UFAL; UFS; UFBA; UFMA; UFRN; UFPB; UFRGS; UFSM; UFC; UFPel; UFGD; UNIFAP; UFPE; UFT. ${ }^{2}$

Após essa primeira etapa, os endereços eletrônicos (sites) dos referidos cursos foram verificados, a fim de que conseguíssemos acesso aos PPCs em que constavam as ementas e bibliografias das disciplinas a serem analisadas. Quando necessário, fizemos contatos via telefone e/ou e-mail com os coordenadores dos cursos, explicitando a natureza da pesquisa e a necessidade de acesso aos PPCs para a efetivação da mesma. O critério de seleção das disciplinas considerou a presença de menção direta no título da disciplina às palavras corpo, corporeidade, movimento e seus derivados. Foram selecionadas, segundo o critério descrito, 37 disciplinas para análise.

No que se seguiu, realizamos levantamento quantitativo das obras de referência das 37 disciplinas analisadas. Resultou dessa iniciativa o reconhecimento da recorrência de algumas obras nas diferentes ementas das disciplinas. Posteriormente, realizamos estudo da relação entre corpo, criação e educação presente no escopo dessas obras.

Por fim, empreendemos análise quantitativa e qualitativa das ementas das 37 disciplinas selecionadas, no que se refere à presença das palavras: técnica(s) (e/ou elemento(s) técnico(s)), criação, cena, ensino, experiência(s), conhecimento(s) e formação, bem como o modo como es-

\footnotetext{
${ }^{1}$ Pesquisa realizada com financiamento da PROPESQ/UFT.

${ }^{2}$ As consultas às instituições se deram entre agosto e dezembro de 2014.
} 
sas palavras apareciam articuladas entre si nas referidas ementas. Nessa medida, este artigo resulta de pesquisa documental com análise quantitativa e qualitativa de dados, segundo categorias predefinidas e anteriormente elencadas.

Não pretendemos com esse texto expor de forma negativa ou comparar instituições de ensino entre si. Portanto, os dados foram tratados sem referência explícita às instituições de que cujos PPCs foram extraídos. O que almejamos, ao contrário, é levantar um relevante tema para a área (Ensino em Teatro) e fornecer fontes de dados para futuras e necessárias discussões sobre as questões expostas nas análises que se seguem.

É importante ressaltar que realizamos um levantamento prévio à pesquisa sobre publicações que tivessem abordado o tema de modo tão específico como propomos. Nenhum material teórico que pudesse nos servir como referência foi encontrado. Nessa direção, essa pesquisa supre certa carência na área: discussões que investiguem pontos específicos sobre a construção dos currículos em teatro, tanto para o ensino superior quanto para a educação básica. Para se ter uma noção da escassez de produções sobre o tema específico abordado neste trabalho, quando buscamos em sites especializados pela indexação de produções científicas, tais como Scielo, utilizando como referência e item de busca as expressões: currículo de teatro, ensino de teatro, formação em teatro, bem como quando se faz uma busca integrada com as palavras currículo e teatro, apenas três artigos são encontrados: Teoria e prática na formação de professores: a prática como tecnologia do eu docente (GARCIA; FONSECA; LEITE, 2013); Reflexões acerca do estágio curricular na formação do professor licenciado em teatro (ALMEIDA JUNIOR, 2013); Espaço inventado: o teatro pós-dramático na escola (ANDRÉ, 2008). ${ }^{3}$ Nos textos em questão, ainda que abordem aspectos específicos do currículo de teatro, em nenhum dos casos, a perspectiva e o objeto de discussão são coincidentes com esta pesquisa, como podemos observar pela leitura dos resumos a seguir:

Este artigo discute a relação teoria e prática nas Diretrizes Curriculares Nacionais para a Formação dos Professores da Educação Básica, no início da década de 2000. Tem como fonte de dados a legislação curricular que instituiu a reforma e os Projetos Pedagógicos de quatro cursos de licenciatura da Universidade Federal de Pelotas (Educação Física, Artes Visuais, Matemática e Ciências Sociais). A partir dos estudos de Michel Foucault sobre a governamentalidade e a ética e de estudos sobre as políticas educacionais e curriculares contemporâneas, mostra os efeitos da nova matriz curricular nos currículos dos cursos investigados. O estudo demonstra que a política oficial reforça o pragmatismo na educação de professores e problematiza a prática como tecnologia do eu docente implicada na formação de um professor prático-reflexivo, em uma visão reducionista das competências e habilidades docentes. (GARCIA; FONSECA; LEITE, 2013, p. 01).

A partir de um breve panorama histórico, busca-se apontar enfrentamentos e dificuldades políticas e culturais em torno da inserção do ensino de teatro, como campo de conhecimento no currículo da Educação Básica. Toma-se como objeto para esta discussão o estágio supervisionado obrigatório e o seu papel na formação do futuro docente. Nesse contexto, os relatos dos alunos estagiários buscam somar à reflexão do estágio curricular obrigatório como espaço de formação do ofício da docência, do diálogo entre os imaginários teatrais vivenciados na formação artística ao longo da formação e aquele realizado pelas práticas escolarizadas e na visibilidade do teatro no território escola. (ALMEIDA JUNIOR, 2013, p. 01).

\footnotetext{
${ }^{3}$ Ainda que a produção online não seja a única ou a mais importante forma de disseminação científica, ela é, sem dúvida, um significativo meio de socialização das pesquisas, sendo, muito provavelmente, o mais democrático. Nessa dimensão, nossa referência aos trabalhos divulgados na internet não abarca toda a produção sobre a área, mas é, sem dúvida, representativa de um quadro mais geral sobre o tema. A escolha por revistas da biblioteca eletrônica Scielo se deu devido ao grande impacto dessa fonte sobre a prática científica brasileira.
} 


\begin{abstract}
Com a publicação da lei n. 9394/96, a arte integra-se ao currículo do ensino básico como área de conhecimento. Neste ensaio, problematiza-se essa nova condição da arte na escola, refletindo a particularidade da experiência artística em relação às outras disciplinas, de modo a não se descaracterizar o que é próprio dela. A partir do entendimento de que a presença da arte é provocadora de mudanças, busca-se observar aquilo que, na escola, é necessário "ser tocado" por ela. Esse olhar investigativo flagra uma cena de destruição, com problemáticas muito próximas daquelas expressas pelo teatro contemporâneo. Com isso, sugere-se aproximar a realidade escolar de formas do teatro pós-dramático, com o intuito de inventar espaços que possam vir a ser coletivos e que acolham o que se chamou de "trocas de intimidades". Dessa aproximação, reitera-se o conceito de conhecimento como invenção, defendido por Michel Foucault, e detecta-se a necessidade de elaborar uma atitude docente que seja provocativa e crie ações educativas de tipo estratégico. (ANDRÉ, 2008, p. 01).
\end{abstract}

Como podemos observar, ainda que resultem das buscas descritas três textos, apenas dois deles versam sobre a linguagem teatral, especificamente, e suas relações possíveis com o ensino e com a educação básica. Assim, na esteira do que foi apresentado nesta introdução, é urgente a necessidade de discussões sobre dimensões transversais e outras específicas sobre a construção de Projetos Pedagógicos das licenciaturas em teatro, no que tange à natureza do ensino e formação do professor de teatro e às funções da inserção do teatro na educação básica. Isto porque, os PPCs são, ou deveriam ser, os principais parâmetros para as atividades em docência, bem como para as funções dos diferentes planos de ensino. Nessa medida, essa pesquisa é apenas um passo dos muitos necessários para um debate próspero sobre o tema, com fins de que possamos realmente construir PPCs e percursos de formação de futuros professores que não estejam exclusivamente pautados em inclinações e desejos pessoais dos muitos professores envolvidos na formação de docentes em teatro em uma mesma universidade.

\title{
2 | DESENVOLVIMENTO
}

\subsection{Omissão e acesso aos Projetos Pedagógicos de Curso: como saber de que natureza de curso se trata?}

Na primeira etapa da pesquisa - levantamento dos PPCs das licenciaturas em teatro das universidades federais brasileiras -, constatamos que, apesar de ser, supostamente, um documento de ordem pública e de livre acesso, no mais das vezes, os PPCs dos cursos não podem ser encontrados com facilidade.

À época da pesquisa, das 24 instituições que ofereciam a supracitada licenciatura, apenas 8 disponibilizavam os PPCs das licenciaturas em teatro em seus sites institucionais (UNIRIO, UFSJ, UFU, UNIR, UFAL, UFSM, UNIFAP) 4 . Ou seja, apenas 1/3 dos documentos atendeu ao princípio do acesso público. Quando entramos em contato com os coordenadores ou responsáveis administrativos pelos cursos das outras 16 instituições de ensino em questão, um segundo grupo composto por 8 universidades disponibilizou seus PPCs (UFMA, UFRN, UFPel, UFRGS, UFC, UFBA, UFG, UFAC). Entretanto, na maioria dos casos, foram necessárias explicitações dos objetivos da pesquisa,

\footnotetext{
${ }^{4}$ Muitos sites institucionais apresentam organizações que dificultam a obtenção das informações desejadas. Nesse sentido, podem haver outras instituições que disponibilizam os PPCs em seus sites institucionais, mas que não foram encontrados pela equipe de pesquisa. Foi por essa razão, que as instituições em questão foram contatadas por telefone e por e-mail.
} 
além, em alguns casos, de autorização de profissionais específicos daquelas instituições para que tivéssemos acesso aos documentos. Ou seja, dadas as condições de obtenção dos PPCs acima descritas, elas evidenciam claramente que o acesso aos mesmos só se dá em condições específicas como a que aqui apresentamos (pesquisa), o que representa certa impossibilidade de contato com os documentos em questão por futuros alunos daquelas instituições de ensino, por exemplo.

Mesmo após contato telefônico e via e-mail, 8 instituições se recusaram a disponibilizar seus PPCs ou não responderam às tentativas de contato (UNB, UFMG, UFPA, UFPB, UFOP, UFS, UFGD, UFPE). Em um desses casos, o responsável administrativo pelo curso afirmou via telefone que o acesso ao documento só seria possível após aprovação da solicitação em colegiado de curso; a mesma foi enviada via email e não foi atendida pela instituição.

Um dos prejuízos dessa omissão dos Projetos Pedagógicos dos Cursos, ou mesmo a dificuldade de acesso a eles, a nosso ver, é a impossibilidade de consulta, para embasar decisões, por exemplo, por qual Universidade optar, por parte de interessados em ingressar nos referidos cursos de formação superior. Futuros alunos, e em muitos casos, alunos em curso, acabam não tendo qualquer possibilidade de reconhecimento das diretrizes que sustentam os cursos de formação dadas as dificuldade de acesso aos documentos em que aquelas estão, ou deveriam estar, explicitadas.

Se o PPC é um documento que norteia as ações educativas, a omissão desse documento é, de certa forma, a omissão da própria natureza do curso e dos percursos de formação adotados neles. Nesse sentido, o aluno acaba escolhendo preponderantemente a universidade em que realizará seu curso de formação por dados referentes à própria instituição, seus prós e contras enquanto instituição, e não, considerando-se a falta de acesso aos PPCs, pela natureza e diretrizes de formação do curso pretendido em cada uma das diferentes instituições.

Desde a Portaria Normativa MEC $n^{\circ} 21$, de 5 de novembro de 2012, alunos de todas as regiões administrativas do país vêm conseguindo cada vez mais acesso às universidades federais brasileiras por programas como o Sistema de Seleção Unificada (SISU/MEC) - sistema informatizado e gerenciado pelo Ministério da Educação, que permite que diferentes instituições de ensino se valham das notas atribuídas aos candidatos no ENEM (Exame Nacional do Ensino Médio) para ingresso em seus cursos de formação. Na direção do que vimos expondo e reiterativamente, esses alunos deveriam poder contar com documentos como os PPCs para pautarem suas escolhas por qual universidade ingressar. Nesse sentido, a omissão dos PPCs acarreta certo prejuízo ao pleno funcionamento do próprio SISU, na medida em que os futuros alunos, mesmo que possuam acesso às diferentes universidades federais, acabam por não terem condições de selecionar a universidade pela natureza do curso que pretendem. Esse fato, supomos, pode, inclusive, ser um dos agravantes dos crescentes quadros de evasão universitária. O difícil acesso aos PPCs esbarra ainda em prejuízos de outras ordens como mobilidades acadêmicas de alunos, que não conseguem antever as possibilidades de validação de disciplinas cursadas em diferentes instituições, bem como de equivalências, em caso de transferências entre instituições.

Não almejamos afirmar que todo ou a maioria dos futuros alunos de um curso de formação superior tenha interesse em pesquisar a natureza do curso em diferentes instituições de ensino. Entretanto, caso queiram fazê-lo, a pesquisa em questão comprovou a impossibilidade de tal iniciativa, pelo menos se tomarmos como referência os documentos que ditam as diretrizes dos cursos (PPCs).

\subsection{Desvínculos entre bases teóricas, prática do ator e o ensino de teatro}

Considerando o que expusemos no tópico anterior, dos 24 cursos de licenciatura em teatro oferecidos por universidades federais brasileiras à época da pesquisa, apenas 16 deles constam das análises que apresentamos a seguir, já que, reiteramos, 8 cursos não disponibilizaram seus PPCs para a realização desta pesquisa. 
Ao todo, foram analisadas bibliografias de 37 diferentes disciplinas das licenciaturas em teatro. Como dissemos anteriormente, o critério de seleção das disciplinas utilizado foi a presença explícita no título da disciplina das palavras: corpo, corporeidade, movimento e seus derivados. Muitos títulos de disciplina que tomam o corpo e suas relações com a educação e com a criação se repetem nos diferentes cursos. Assim, as disciplinas cujas bibliografias e ementários foram analisadas são assim nomeadas: Artes do Corpo; Consciência Corporal; Corpo e Movimento; Corpo e Voz; Corpo, Expressão e Criatividade; Espaço, Corpo e Movimento; Expressão Corporal; Expressão Corporal e Vocal; Expressão Corporal e Vocal para o Teatro na Educação; Movimento e Pedagogia; Preparação Corporal; Princípios da Expressão Corporal: dança pessoal e composição de figuras; Técnicas Corporais;

Aparecem no todo das bibliografias básicas das 37 disciplinas analisadas 94 obras de referência. No que se referem às bibliografias complementares, 37 obras são citadas. Dessas últimas, 17 também constam naquelas primeiras. Portanto, entre bibliografias básicas e complementares das disciplinas analisadas existem 111 diferentes títulos de obras tomados como referência nos diversos PPCs em questão. Entre essas, 53 são adotadas em apenas uma das 37 disciplinas analisadas e outras 22 são citadas em duas diferentes bibliografias dos cursos analisados. Ou seja, essas 75 obras parecem atender a objetivos bastante específicos em aspectos determinados dos planos de trabalho dos cursos. Essa afirmação se dá na medida em que, caso fossem consideradas referências indispensáveis à área, deveriam aparecer e provavelmente constariam em um número maior de bibliografias, supomos.

Nessa mesma direção, apesar da grande diversidade de obras de referências nas bibliografias básicas e complementares, os dados analisados demonstraram que apenas 6 títulos são elencados por número igual ou superior a 5 vezes no montante total das disciplinas em questão, sendo o maior número de aparições da obra em bibliografias básicas. A obra Eutonia: um caminho para a percepção corporal (ALEXANDER, 1983), apesar de ter recorrência igual a 5 vezes, apenas 2 vezes se referem à bibliografias básicas, as outras 3 aparições se dão em bibliografias complementares. Considerar 5 citações entre 37 disciplinas de uma mesma natureza, significa reconhecer uma recorrência mínima de $13,51 \%$ entre os ementários, o que ainda não representa uma efetiva presença da obra no todo dos dados analisados.

O livro Domínio do Movimento (LABAN; ULMAMN, 1978) é citado 17 vezes em bibliografias básicas e outras 3 vezes em bibliografias complementares, sendo a obra de maior recorrência entre as 111 existentes, com índice igual a 54,05\% de presença nos ementários. A obra A Arte Secreta do Ator. Dicionário de Antropologia Teatral (BARBA; SAVARESE, 1995) é tomada como bibliografia básica por 5 diferentes disciplinas e 2 vezes como complementar, sendo a segunda obra de maior referência, com índice de presença nos ementários igual a 18,91\%.

Esses dados iniciais demonstram que existe apenas uma obra, até então, reconhecida pelos especialistas da área como um título significativo e de grande valia às discussões sobre a relação entre corpo, educação e criação (Domínio do Movimento). Isso pode ser observado pela discrepante recorrência entre esta obra e a segunda de maior referência nos ementários das licenciaturas em teatro no Brasil, no que se refere ao tema aqui em estudo. Se tomarmos apenas as bibliografias básicas, a primeira obra aparece 17 vezes $(45,94)$ enquanto a segunda apenas 5 vezes $(13,51 \%)$.

A preponderância da obra de Laban sobre as demais na área pode ser reconhecida também quando se leva em conta que a quarta - O Ator Compositor (BONFITTO, 2002) - e quinta - O Papel do Corpo no Corpo do Ator (AZEVEDO, 2002) - obra de maior referência em quantidade de citações nas bibliografias, 6 (5 básicas; 1 complementar) e 5 (4 básicas; 1 complementar), respectivamente, também se referem, em capítulos e/ou subcapítulos específicos, aos escritos de Laban. 
A terceira e a sexta obra de maior recorrência entre as citações em bibliografias são, respectivamente, Corpomente: uma síntese do caminho do oriente e do ocidente para a autoconsciência, saúde e crescimento pessoal (DYCHTW ALD, 1984), com 6 citações em bibliografias básicas, e Em Busca de um Teatro Pobre (GROTOVSKI, 1971), com 3 citações em bibliografias básicas e outras 2 em bibliografias complementares, como pode ser observado na tabela a seguir:

Tabela 1 - Obras de maior recorrência em quantidade de citações nas bibliografias das disciplinas analisadas.

\begin{tabular}{|c|c|c|c|}
\hline Referências Bibliográficas & $\begin{array}{l}\text { Citações em } \\
\text { Bibliografias } \\
\text { Básicas }\end{array}$ & $\begin{array}{c}\text { Citações em } \\
\text { Bibliografias } \\
\text { Complementares }\end{array}$ & Total de Citações \\
\hline $\begin{array}{l}\text { LABAN, Rudolf; ULMAMN, Lisa. Domínio do } \\
\text { movimento. São Paulo: Summus, } 1978 .\end{array}$ & 17 & 3 & 20 \\
\hline $\begin{array}{l}\text { BARBA, Eugenio; SAVARESE, Nicola. A arte se- } \\
\text { creta do ator: dicionário de antropologia teatral. } \\
\text { Campinas: HUCITEC; Ed. UNICAMP, } 1995 .\end{array}$ & 5 & 2 & 7 \\
\hline $\begin{array}{l}\text { DYCHTW ALD, Ken. Corpomente: uma síntese } \\
\text { do caminho do oriente e do ocidente para a au- } \\
\text { toconsciência, saúde e crescimento pessoal. São } \\
\text { Paulo: Summus Editorial, } 1984 \text {. }\end{array}$ & 6 & - & 6 \\
\hline $\begin{array}{l}\text { BONFITTO, Matteo. O ator compositor. São Pau- } \\
\text { lo: Perspectiva, } 2002 .\end{array}$ & 5 & 1 & 6 \\
\hline $\begin{array}{l}\text { AZEVEDO, Sônia Machado de. O papel do corpo } \\
\text { no corpo do ator. São Paulo: Perspectiva, } 2002 .\end{array}$ & 4 & 1 & 5 \\
\hline $\begin{array}{l}\text { GROTOWSKI, J. Em busca de um teatro pobre. } \\
\text { Tradução Aldomar Conrado. Rio de Janeiro: Civi- } \\
\text { lização Brasileira, } 1971 .\end{array}$ & 3 & 2 & 5 \\
\hline
\end{tabular}

Fonte: Dados extraídos de Projetos Pedagógicos de 24 licenciaturas em teatro de universidades federais brasileiras.

A tabela 1 nos permite depreender que das 6 obras de maior recorrência nas bibliografias das disciplinas analisadas, 4 dos títulos estão estritamente voltados para a formação, trabalho e pesquisa do ator, sem vínculos diretos com reflexões a respeito da inserção do ensino de teatro na educação formal. Considerando que estamos apresentando análises de parte dos Projetos Pedagógicos de Cursos de Licenciatura, supomos que a preocupação com o Ensino Básico deveria estar evidente em todas as disciplinas e referenciais bibliográficos adotadas, especialmente no que tange àqueles com maior recorrência.

Apesar de aparecerem duas obras na tabela, as quais estão, de certa forma, voltadas para as relações entre corpo e conhecimento no cotidiano (Domínio do Movimento; Eutonia), elas não estão diretamente articuladas com o ensino específico do teatro. Essa situação reflete o contexto mais amplo das 111 obras citadas nas diversas bibliografias, as quais, quando não se referem ao trabalho estrito do ator, podem ser reconhecidas em quatro grandes grupos: 1 - Pesquisas e escritos em e sobre dança, tais como: A escuta do corpo: sistematização da técnica Klauss Vianna (MILLER, 2007); 2 - Teorias da Psicomotricidade, a exemplo de: A coordenação motora: aspectos mecânicos da organização psicomotora do homem (BEZIERS, 1992); 3 - Propostas de Educação Somática, entre elas: Eutonia e relaxamento (BRIEGHEL-MÜLLER, 1987); 4 - Discussões a partir da filosofia, como em: Fenomenologia da Percepção (MERLEAU-PONTY, 1994).

Esses dados revelam a quase inexistência de escritos com ampla divulgação e aceitação pelos professores da área, voltados para a articulação entre aspectos da pesquisa e prática corporal do ator especificamente e o ensino de teatro voltado para a educação básica formal, foco principal 
das licenciaturas em teatro das universidades federais brasileiras. A análise das bibliografias revelou que a pesquisa sobre corpo na educação em contexto teatral depende majoritariamente de textos em artes voltados para a dança.

Além da já explicitada escassez de bibliografias específicas sobre o corpo e educação no contexto do ensino de teatro, verificamos que as referências analisadas, pela quantidade e natureza das obras, evidenciam que o corpo predominante nas disciplinas estudadas é o corpo-ator, voltado para a prática teatral, e não o corpo-aluno, direcionado para o cotidiano, contradizendo o objetivo principal da formação naqueles cursos: o futuro professor de teatro para educação básica e não a profissionalização para a carreira em teatro, que também pode acontecer, mas não como objetivo primeiro da formação.

\subsection{Discrepâncias conceituais: atritos entre a prática do ator e o ensino nos ementários das licenciaturas em teatro}

No que se segue, tentaremos reconhecer se o aparente desvínculo entre o trabalho corporal do ator na formação do futuro professor de teatro e discussões sobre o ensino de teatro na educação básica formal está presente, para além das bibliografias, como demonstra a análise precedente, também nas ementas das disciplinas em questão. Para tanto, decidimos realizar a análise dos ementários a partir de duas categorias de palavras: 1 - Referentes ao Trabalho do Ator, por meio da presença das palavras "técnica(s) (e/ou elemento(s) técnico(s)), criação e cena"; 2 - Referentes ao Ensino de Teatro na Educação Básica, pela presença das palavras "ensino, experiência(s), conhecimento(s), formação e educação". Acreditamos que essas duas categorias revelam possibilidades de diálogo entre corpo, teatro e educação, dado o contexto em que se insere esta pesquisa.

As palavras elencadas nas duas categorias de análise aparecem em 29 ementas entre as 37 analisadas. As outras 8 ementas que não continham nenhuma das palavras buscadas para compor as duas categorias em questão, apresentaram textos sobre os objetivos das disciplinas voltados para consciência corporal e/ou ampliação da expressividade corporal, sem destacar o contexto de pesquisa e a inserção dos processos que pretendem (trabalho do ator e/ou ensino de teatro), na maioria das vezes associados a referências bibliográficas voltadas para a dança e/ou para a educação somática. Em um caso e no outro, como já apontamos, a especificidade do trabalho do ator não aparece no corpo do texto da ementa, tampouco em obras de referência. Dada à falta de delimitação contextual dos procedimentos e objetivos do ensino descritos naquelas ementas, as mesmas disciplinas não puderam ser enquadradas em uma das duas categorias selecionadas por nós para análise. Visto que essas 8 disciplinas poderiam tanto atender a demandas de experiência e discussão sobre a formação do ator quanto ao ensino de teatro na educação básica. Nesses casos, supomos que inclinações pessoais dos professores responsáveis pela disciplina é que determinam o foco das mesmas.

Entre as disciplinas analisadas, apenas 11 apresentaram uma das palavras vinculadas à categoria Ensino de Teatro na Educação Básica. Todavia, dessas 11 disciplinas, e em 4 delas, as palavras estavam diretamente associadas à prática e performance do ator e não ao ensino propriamente dito, como por exemplo nos trechos a seguir, retirados de ementas analisadas: "Formação da fisicalidade cênica baseada na observação externa em sincronia com a auto observação". "[...] sistematizando um conhecimento a respeito de técnicas e treinamentos corporais para o intérprete". Como podemos observar, nos dois casos, as palavras formação e conhecimento, apesar de constarem na lista das palavras relativas à categoria Ensino de Teatro na Educação Básica, não estão pensadas em relação ao ensino de teatro efetivamente, senão em relação ao trabalho do ator em essência. Ou seja, em apenas 7 das 37 ementas estão descritos explicitamente objeti- 
vos e conteúdos a serem abordados pelo professor, vinculados ao ensino de teatro e não exclusivamente à prática teatral.

Por outro lado, em 3 dessas 7 ementas com descrição de objetivos sobre o ensino de teatro na Educação Básica, não há qualquer menção ao trabalho do ator - palavras relativas à outra categoria que utilizamos para análise nesta pesquisa. Nessa direção, apenas 4 disciplinas, das 37 analisadas, apresentam ementas que articulam textualmente pesquisas e processos de criação de ator e a inserção dos mesmo no contexto da Educação Básica, no que se refere às práticas corporais.

Das ementas analisadas, 17 descrevem objetivos, procedimentos e conteúdos específicos do trabalho do ator, sem qualquer apontamento para a inserção dos mesmos no contexto do Ensino Básico. Uma das ementas, ainda que apresente uma das palavras que foram tomadas por nós como representativas da categoria Trabalho do Ator (técnicas), não explicita textualmente o contexto dessa categoria, como podemos observar no trecho a seguir, retirado de tal ementa: "Desenvolvimento de exercícios e técnicas corporais a partir de um enfoque multidisciplinar". Portanto, essa disciplina integrou o conjunto das ementas (nove ao todo), cujos conteúdos não puderam ser associados a uma ou outra categoria tomada por nós como base para as análises que aqui apresentamos.

O gráfico a seguir resume os resultados apresentados quanto à análise das disciplinas segundo as categorias Trabalho do Ator e Ensino de Teatro na Educação Básica.

Gráfico 1 - Proporção das disciplinas segundo categorias de análise.

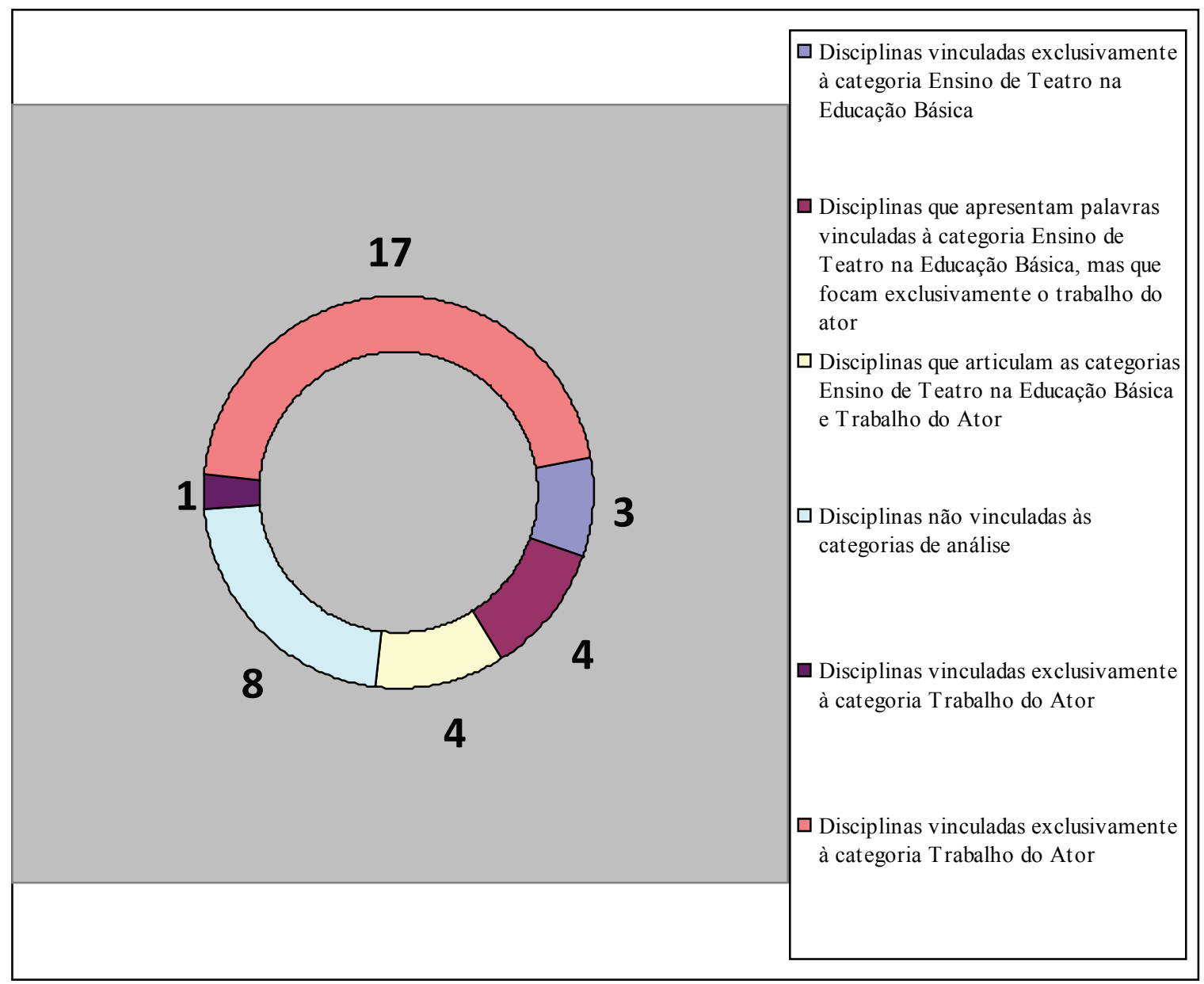

Fonte: Elaborado pelos autores 
Como pode ser observado no gráfico e reiterativamente, as análises aqui empreendidas sobre as ementas das disciplinas em questão deixam evidente a primazia do foco no trabalho do ator, em detrimento de discussões sobre a relação entre esse trabalho e a inserção do mesmo no contexto da Educação Básica. Nessa medida, podemos afirmar que tanto as referências bibliográficas quanto as ementas das disciplinas que tomam o corpo como foco, nas licenciaturas em teatro das universidades federais brasileiras, mantêm certo desvínculo entre propostas de estudo e prática sobre o trabalho do ator e estudos e propostas didático-metodológicas para a inserção do teatro na Educação Básica, bem como as funções para tal inserção.

Resultou também desta pesquisa que dos 16 ementários analisados, em 11 cursos as disciplinas com foco no corpo são organizadas sequencialmente, tais como: Expressão Corporal I, II e III; Técnicas Corporais I e II; Corpo e Voz I, II, III e IV. Quando observamos esses blocos sequenciais de disciplinas, tomando-se como referência nossas duas categorias de análise, constatamos que apenas 1 dos 11 blocos tem todas as disciplinas vinculadas à categoria Ensino de Teatro na Educação Básica. Dos 10 restantes, mais precisamente em 5, todas as disciplinas sequenciais estão associadas exclusivamente à categoria Trabalho do Ator. Os outros 5 blocos de disciplinas apresentam algum vínculo com a categoria Ensino de Teatro na Educação Básica. Esse vínculo se dá, entretanto, nas disciplinas iniciais (Expressão Corporal I, por exemplo), em direção à progressiva especialização do trabalho do ator, como em: técnica corporal e ensino de teatro na disciplina 1 e apenas técnicas de trabalho do ator nas disciplinas 2 e 3.

Dois últimos dados de análise que nos parecem relevantes e preocupantes ressaltam-se o fato que em nenhuma das ementas analisadas a palavra experiência foi encontrada, quer seja vinculada ao ensino, quer seja vinculada à prática teatral, assim como o que concerne sobre o estudo das potencialidades expressivas e comunicativas do corpo, o qual aparece associado a discussões sobre matrizes e diversidades culturais em apenas uma das disciplinas analisadas.

Resulta, portanto, das análises apresentadas o constante desvínculo nos ementários pesquisados entre o estudo de técnicas teatrais, no que tange ao corpo em cena, e a valia de tal estudo para as práticas docentes em teatro na escola, bem como a não valorização das especificidades contextuais e experiências do corpo-aluno.

\section{3 | PELA CONSOLIDAÇÃO DE UM CAMINHO PRÓPRIO AO ENSINO DE TEATRO}

A maciça presença de obras de referencia de técnicas de trabalho do ator e a significativa preponderância da categoria Trabalho do Ator sobre a categoria Ensino de Teatro na Educação Básica nas ementas das disciplinas com foco no corpo das licenciaturas em teatro das universidades federais brasileiras, parecem refletir o "fantasma da 'bacharelização' da licenciatura"5, tão frequente em falas de alunos e professores daqueles cursos de formação.

Observou-se nas falas de docentes e discentes, em eventos científicos e reuniões da área reclamações pertinentes às ações empreendidas e interesses declarados por colegas de curso,

\footnotetext{
${ }^{5}$ O termo "bacharelização" está aqui empregado na direção de pensar um desvio da formação da identidade característica do professor de teatro para a formação específica do artista cênico (na maioria dos casos, do ator). Ainda que esse não seja um conceito ou uma noção desenvolvida, sua presença pode ser encontrada em autores de outras áreas como na história (GARCIA, 2007) e na química (SÁ, 2012). Nesse segundo caso, o "desvio bacharelizante", segundo a autora, pode se tornar uma cultura dos modos de pensar e operar os currículos e até mesmo uma categoria de análise desse tipo de documento e de discursos sobre a formação nas licenciaturas (SÁ, 2012, p. 46, 114 e 142). A obra de Sá, ainda que seja relativa a outra área do conhecimento é bastante ilustrativa da visão dos alunos sobre a díade licenciatura-bacharelado na direção em que estamos seguindo nesse texto.
} 
mesmo quando vinculados às licenciaturas, afirmando que estes estão bastante mais voltados para práticas essencialmente características dos bacharelados em teatro.

O desconhecimento por parte dos alunos da natureza e objetivo dos cursos de licenciatura faz com que os discentes acabem por não compreender as reais funções daqueles percursos de formação. Por outro lado, a constante identificação de professores das licenciaturas em teatro, com a formação do ator, pode, por sua vez, conduzir e potencializar os processos dessa "bacharelização".

A fragilidade dos PPCs no que tange ao vínculo e objetivo dos cursos de formação de professores com o Ensino Básico e na direção das análises apresentadas, facilita desvios metodológicos e conceituais das práticas da sala de aula (preparação do futuro professor para o contexto da educação), para o trabalho do ator, reduzindo, inclusive, na maioria das vezes, a noção de teatro ao papel do ator na arte da cena. Tal fragilidade pode ser observada na medida em que, constantemente, as discussões de ordem metodológica e didática, quanto ao ensino de teatro, só constam em disciplinas estritamente voltadas para a metodologia, tais como: Metodologia e Prática do Ensino de Teatro, tomando como exemplo o fato que nas ementas das disciplinas analisadas, as palavras metodologia e didática não aparecem em qualquer dos textos. Fica evidente, quando se olha para os ementários sob esse prisma, que as discussões sobre a formação em teatro e o ensino de teatro na Educação Básica estão quase sempre caminhando paralelamente e não de forma articulada.

Esse fato se deve, supomos, em grande medida, da insuficiência de obras de referência na área, bem como da fragilidade de outras, que nos ajudem a refletir sobre caminhos de integração entre esses dois universos que compõem a nossa pesquisa, o trabalho do ator e o ensino de teatro. Esse contexto faz, em parte, com que as referências bibliográficas utilizadas nas licenciaturas em teatro, no nosso caso, especificamente, nas disciplinas que tem o corpo como foco, sejam oriundas de áreas afins ao ensino de teatro.

A interdisciplinaridade só é possível na medida da existência de disciplinas claramente diferentes. Na esteira desse pensamento, é necessário que se estruture e organize o alicerce prático, conceitual, didático e metodológico do ensino de teatro para a Educação Básica, para que a interdisciplinaridade se torne efetiva e produtiva também para a área.

Torna-se assim necessário que se considere que os PPCs não refletem integralmente as práticas e caminhos desenvolvidos nas salas de aula. Todavia, são eles os documentos que organizam a coerência de percurso entre as diferentes iniciativas de formação dos diversos docentes de um curso, asseguradas as inclinações didático-metodológicas de cada professor, com fins de possibilitar a integralidade da formação do futuro profissional do e para o ensino de teatro.

Observa-se que o estudo ora apresentado não resolve ou dissolve os problemas apresentados, mas faz emergir situações que precisam ser visualizadas com maior apuro e precisão ora o descuido com a natureza da formação do docente em teatro; ora a desarticulação entre prática e ensino de teatro; ora, ainda, a ausência de discussões didático-metodológicas em todo o percurso do aluno em formação, e não só em momentos e disciplinas específicos.

Muitas das universidades pesquisadas afirmaram que estavam em processos de revisão e mudança dos seus PPCs o que torna evidente a necessidade constante de ajustes dos documentos que norteiam os currículos. Torna-se necessário o aumento do quantitativo de pesquisas como esta, a fim de que sejam construídas diretrizes para as propostas de formação docente em teatro. Além do que, identificar e registrar a escassez de obras de referência que nos ajudem a pensar as problemáticas da articulação entre o trabalho em teatro e o ensino básico pode incentivar novos pesquisadores a realizarem estudos e produções artísticas e científicas, com fins de que possamos empreender iniciativas que garantam obras de referências especificas para a nossa área: o ensino de teatro na educação básica. 


\section{Referências}

ALEXANDER, G. Eutonia: um caminho para a percepção corporal. São Paulo: Martins Fontes, 1983.

ALMEIDA JUNIOR, J. S. de. Reflexões acerca do estágio curricular na formação do professor licenciado em teatro. Educ. Rev., v. 29, n. 2, p. 43-64, jun. 2013.

ANDRÉ, C. M. Espaço inventado: o teatro pós-dramático na escola. Educ. Rev., n. 48, p. 125-141, dez. 2008.

AZEVEDO, S. M. de. O papel do corpo no corpo do ator. São Paulo: Perspectiva, 2002.

BARBA, E.; SAVARESE, N. A arte secreta do ator: dicionário de antropologia teatral. Campinas: HUCITEC; Ed. UNICAMP, 1995.

BEZIERS, M.-M. A coordenação motora: aspectos mecânicos da organização psicomotora do homem. São Paulo: Summus, 1992.

BONFITTO, M. O ator compositor. São Paulo: Perspectiva, 2002.

BRASIL. Ministério da Educação. Secretaria de Educação Fundamental. Parâmetros curriculares nacionais: arte. Brasília, DF: MEC; SEF, 1997.

BRASIL. Portaria Normativa $\mathrm{n}^{\circ} 21$, de 5 de novembro de 2012. Dispõe sobre o Sistema de Seleção Unificada Sisu. Diário Oficial da União, Brasília, DF, 06 nov. 2012. p. 08-09.

BRIEGHEL-MÜLLER, G. Eutonia e relaxamento. São Paulo: Manole, 1987.
DYCHTW ALD, K. Corpomente: uma síntese do caminho do oriente e do ocidente para a autoconsciência, saúde e crescimento pessoal. São Paulo: Summus Editorial, 1984.

GARCIA, R. C. Jogos, Narrativas e Brincadeiras: Olúdico na formação do professor de história e a bacharelização das licenciaturas. In: Encontro de História Oral do Centro Oeste, 2007, Cáceres. Caderno de Programação e Resumos. Cáceres: Editora da UNEMAT, 2007. v. 1. p. 142-143.

GARCIA, M. M. A.; FONSECA, M. S. da; LEITE, V. C. Teoria e prática na formação de professores: a prática como tecnologia do eu docente. Educ. Rev., v. 29, n. 3, p. 233-264, set. 2013.

GROTOWSKI, J. Em busca de um teatro pobre. Tradução Aldomar Conrado. Rio de Janeiro: Civilização Brasileira, 1971.

LABAN, R.; ULMAMN, L. Domínio do movimento. São Paulo: Summus, 1978.

MERLEAU-PONTY, M. Fenomenologia da percepção. São Paulo: Martins Fontes, 1994.

MILLER, J. A escuta do corpo: sistematização da técnica Klauss Vianna. São Paulo: Summus, 2007.

SÁ, C. S. da S. Currículo ativo e a constituição de identidades profissionais em um curso de licenciatura em química. 2012. 302 f. Tese (Doutorado em Educação)Universidade de Brasília, Brasília, DF, 2012. 